\title{
A REESCRITURA DA MORAL
}

\author{
The re-writing of moral
}

$\underline{\text { José Nedel }}$

UNISINOS

\begin{abstract}
Resumo. O autor deste ensaio parte da constatação de uma intensa ânsia de novidade, que se manifesta na filosofia e na cultura em geral, principalmente desde a modernidade, com preponderância nos dias atuais, de modo especial na área da ética aplicada. Observa que novidade não tem compromisso com verdade; razão mesma do interesse em examinar se e em que medida a moral pode ou deve ser reescrita, como propõem alguns próceres do pensamento nos últimos tempos. Apresenta a posição ambígua de Hans Jonas, que ora postula uma nova moral, ora defende a permanência de valores e normas da moral comum. Traz também à colação o entendimento de Michel Serres, que propõe a substituição ou a emenda do contrato social por um contrato natural, em que a natureza - nela incluídos os animais - adquira status de sujeito jurídico, deslocando desta forma o homem de seu lugar privilegiado e central na ética como único sujeito de direito. Apresenta de forma sumária a posição de Peter Singer, que propõe a substituição de alguns dos princípios da ética tradicional, por outros que, em verdade, são os mesmos velhos princípios, porém "reescritos" por ele. Menciona ainda outros pensadores, cujas propostas vão mais ou menos no mesmo sentido. Desenvolvendo sua tese, em oposição aos que defendem a renovação radical ou a rejeição in totum da ética clássica, sustenta a utilidade, ou mesmo a necessidade, em alguns casos, da complementação ou renovação parcial da ética comum, mediante conclusões e determinações (ou especificações), a partir dos princípios primários da lei moral natural, de acordo com as exigências dos tempos que fluem. Dessa maneira, não acolhe a opinião dos que têm a ética tradicional como incapaz de dar conta das novas questões exsurgidas com o espantoso desenvolvimento da ciência e da tecnologia, nomeadamente na área da biotecnologia. A tese específica é a da união saudável do antigo, devidamente joeirado, de valor permanente, e do novo, que não conflite com a verdade e a razoabilidade, de acordo com a sabedoria comum da humanidade. É o que expressa o conhecido adágio nova et vetera, que aponta para a necessidade da renovação, sem o abandono dos valores tradicionais autênticos, unindo o antigo que permanece valioso com o novo que vem para enriquecer o patrimônio cultural da humanidade.
\end{abstract}

Palavras-Chave: ética aplicada, H. Jonas, M. Serres, P. Singer, ética tradicional, biotecnologia

Abstract. My starting point is the surge for novelty in the philosophy and culture in general since modernity and that is prevailing on present days, especially on the applied ethics field. A novelty which is not committed to truth, a fact that calls for an examination of the question about we can or should rewrite morality, as some authors affiliated to the novelty sustain. So I analyze Hans Jonas's, Michel Serres's, and Peter Singer's positions about the subject. My thesis is that we should call for a healthy union of the old and the new ethics, one that is related to the truth and reasonable and convergent to the common wisdom of humanity. We 
must to put together the permanent values of ancient and the new ones that comes to enrich the human culture.

Key-Words: Applied ethics, H. Jonas, M. Serres, P. Singer, traditional ethics, biotechnology

1 - Novidade e verdade. A ânsia de novidade, com maior ou menor desprezo da tradição, é uma das características do pensamento moderno e pós-moderno. Já René Descartes declarou: "Tanto mais idônea seria a inteligência para o conhecimento da verdade, quanto menos houvesse aprendido do que até então se havia chamado filosofia" (Princípios de filosofia, VI). Por sua vez, Francis Bacon pretendeu uma instauratio ab imis fundamentis, ou seja, uma inovação radical da ciência desde os seus mais profundos alicerces (Novum Organon, I). Immanuel Kant apresentou-se como reformador, disposto a desencadear na filosofia uma revolução semelhante à de Nicolau Copérnico na ciência dos astros. E ainda Augusto Comte, através de uma "filosofia nova", sonhou com a pacificação geral dos espíritos e a própria regeneração da humanidade (Cours de philosophie positive, VI).

O desejo imoderado de inovação, que anima corifeus do pensamento moderno, invade também todo o período contemporâneo e o agora por muitos chamado pós-moderno, até nossos dias. O resultado é a enorme dispersão doutrinal reinante na cultura hodierna. Cada qual procura sua verdade, pretensamente nova, singular, original, como se até o momento nada de verdadeiro tivesse sido pronunciado.

Em matéria de ética aplicada, autores há que propõem uma revolução completa na filosofia moral, como se a filosofia clássica, do senso comum, fosse maneta, ineficiente, sem qualquer perspectiva de solução para os problemas emergentes na área social e ambiental, nesta época. Com o nobre intuito de preservar os animais, o meio ambiente, o planeta, chegam ao cúmulo de propor a atribuição de direitos aos animais e à natureza como um todo; o que é apto a produzir verdadeiro frisson nos adeptos da filosofia e do 
direito até hoje forjados no Ocidente. Em matéria de ética da vida e da saúde, há quem proponha a reescritura de velhos princípios morais, dando-lhes novas formulações, em substituição aos princípios morais da tradição ocidental.

Novidade, contudo, não tem compromisso com verdade. A maior parte das verdades que sustentam a vida e a conduta das pessoas não são novas; e uma enxurrada de novidades obviamente não são verdadeiras. Em face disso, aparece nítida a importância de examinar se e em que medida a moral deve ser rescrita.

2 - Posição de Hans Jonas. 2.1 - Nova ética. Hans Jonas clama insistentemente por uma "nova ética" (1995, p. 56, 59, 230; 1997, p. 177), para fazer face às questões suscitadas pela tecnociência. Proclama que “novas formas de poder exigem também novas normas éticas" (1997, p. 178). Segundo ele a crise em que se encontra a humanidade exige uma filosofia moral que, dispensando o formalismo (Kant), o progressismo da razão absoluta (Hegel), o utopismo (Marx, Bloch) e o antropocentrismo em geral, saiba fixar as normas mínimas para a sobrevivência do homem e da natureza. Dessas normas seria preciso tirar, mais do que a determinação positiva do sentido do agir, a proibição do que em absoluto não deve ser feito, pois "nunca é lícito apostar... a existência ou a essência do homem em sua totalidade" (1995, p. 80). Estaria vedado o tudo ou nada nos assuntos em que está implicada a humanidade $(1995$, p. 81,88$)$. Semelhante aposta representa, para o autor, "o pecado mortal ético e principalmente metafísico, do qual a humanidade pode tornar-se culpável" (1995, p. 298). Jonas entende que nenhuma ética ou metafísica anterior proporciona os princípios para enfrentar as novas questões, muito menos é portadora de uma doutrina já pronta para essa finalidade (1995, p. 34); que há valores novos a se imporem, como o da máxima informação sobre as conseqüências de nossas ações 
coletivas - campo em que precisamente houve mudança radical - devendo acrescentar-se, entre outras coisas, a ciência de que o homem deve ser (existir), a renúncia a certas liberdades, especialmente a que se refere ao crescimento do poder tecnológico e aos riscos de autodestruição dele decorrentes, bem como o sentimento de humanidade... (1997, p. 41-54).

2.2 - Ambigüidade. De outra parte, o próprio Hans Jonas está em dúvida sobre se a ética tradicional é capaz ou não de oferecer solução para as novas questões (1997, p. 193). De fato, a afirmação da novidade radical que seria postulada, segundo vários textos seus, é contrabalançada por outros, em que admite a continuação da vigência das virtudes antigas (1997, p. 41-54). A pretensão ali manifestada não é de eliminar as virtudes tradicionais, mas de complementá-las e a elas acrescentar novas dimensões segundo as exigências do tempo. A novidade postulada não implicaria, portanto, perder de vista as antigas normas éticas, as velhas virtudes cardeais. Em verdade, segundo o autor, há valores de ontem que persistirão amanhã, sobretudo para a esfera mais imediata, tais como os preceitos da honradez, do respeito, da justiça, da caridade etc. Da mesma forma, continuarão vigentes a responsabilidade agora com novas dimensões - a austeridade e a moderação. Esta última, todavia, não tem hoje tanto a ver como outrora com a escassez e a perfeição pessoal, porém mais com a contenção do poder, ou seja, com a manutenção das próprias existências na Terra. Em suma, não se trataria de substituir uma ética por outra, mas de "adicionar ao catálogo de obrigações... outras novas, que nunca foram consideradas, porque não havia ocasião para isso" (1997, p. 178).

2.3 - Sumária apreciação. Pelo visto, o autor se manifesta vacilante, para não dizer contraditório. Por esse motivo, sua tese radical deve, no mínimo, ser relativizada, de molde a não contrastar com a velha tradição. Salta aos 
olhos que a fórmula do imperativo moral proposta por Jonas é basicamente a de Kant, com a diferença de que "sai do domínio hermético do individual para o território mais amplo do coletivo", razão por que "parece... mais adequado se considerar que os imperativos de Jonas e Kant não se excluem, mas sim, complementam-se" (Siqueira, 1998, p. 94).

A este respeito, Robert Bernstein, professor da Faculdade de Filosofia de Nova lorque, detectou em Jonas uma "tendência ao exagero e à hipérbole", exatamente quando sugere a necessidade de rompimento completo com a ética tradicional. Entende que o pensador deveria especificar outros princípios morais, além do de responsabilidade, e o que deve ser preservado e defendido nas várias formas de ética tradicional (1995, p. 13-20; ver Siqueira, 1998, p. 90, 96, 97).

3. Posição de Michel Serres. 3.1 - Ética coletiva. Segundo Michel Serres, em face das condições atuais da natureza, necessitamos de "uma ética coletiva diante da fragilidade do mundo" (1991, p. 94). Aliás, segundo ele, a teoria do contrato social apenas repete tautologicamente a necessidade das ligações coletivas (1991, p. 75). O motivo seria, além de outros, que o ser-aí individual só é capaz de obter no mundo global um efeito similar ao do bater de asas de uma borboleta, num deserto da Austrália, sobre as pradarias da verde Erin, de acordo com a imagem de Swift (1991, p. 29).

3.2 - Nova política. Serres afirma: "Tudo acaba de mudar. De agora em diante consideraremos inexata a palavra política, pois ela se refere apenas à cidade, aos espaços publicitários, à organização administrativa dos grupos. 0 que mora na cidade, antigamente chamado burguês, nada conhece do mundo. De agora em diante o governante deve abandonar as ciências humanas, as ruas e os muros da cidade, tornar-se físico, emergir do contrato social, inventar um novo contrato natural voltando a dar à palavra natureza o 
sentido original de condições em que nascemos - ou deveremos amanhã renascer" (1991, p. 56). E continua: "O físico, no sentido grego mais antigo e também o mais moderno, aproxima-se da política" (1991, p. 57); [Aliás] “a física já proporciona a idéia do contrato natural" (1991, p. 71).

3.3 - Contrato natural. A novidade que Michel Serres apresenta é a substituição do velho contrato social, que liga as pessoas entre si, sem consideração à natureza, por um contrato natural no qual esta, a natureza, também seja considerada como verdadeiro sujeito jurídico. O autor afirma que ao contrato social se deve unir um contrato natural (1991, p. 122). "Este [o contrato social] nos reuniu, para o melhor e para o pior, ... sem mundo; agora que sabemos nos associar diante do perigo, é preciso prever, ... um novo pacto a assinar com o mundo: o contrato natural" (1991, p. 25). Aliás, segundo ele, "um contrato não pressupõe obrigatoriamente a linguagem: basta um jogo de cordas. Elas compreendem sem palavras" (1991, p. 125). É visto que a Terra nos fala em termos de forças, ligações, interações - "o que basta para fazer um contrato" (p. 52). Por isso, segundo Serres, "não temos necessidade de linguagem para que esse contrato funcione, como um jogo de forças" (1991, p. 127). Trata-se de um contrato não assinado, mas é "virtual", "metafísico"... (1991, p. 59), que reconhece um equilíbrio entre a nossa potência atual e as forças do mundo, entre a força de nossas intervenções globais e a globalidade do mundo. Em suma, leva-nos a considerar o "ponto de vista do mundo em sua totalidade" (1991, p. 59).

O mencionado contrato natural será de simbiose e reciprocidade (1991, p. 51). "As instituições criadas pelos grupos dependerão de agora em diante dos contratos explícitos que firmarão com o mundo natural, nunca mais um bem nosso, nem privado nem comum, mas de agora em diante nosso simbiota" (1991, p. 57). "A humanidade astronauta flutua no espaço como um feto no 
líquido amniótico, ligada à placenta da Mãe-Terra por todas as vias nutrientes" (1991, p. 140).

Segundo Serres, "vivemos contratualmente com a Terra, desde há pouco. ... Eqüipolentes a ela, nos tornamos o biplaneta da Terra, que se torna também o nosso biplaneta... Nova revolução, no sentido copernicano, para nossa grandeza e nossas responsabilidades. $O$ contrato natural se parece com um contrato de casamento, para o pior e para o melhor" (1991, p. 128).

3.4 - Cosmocentrismo. A palavra "meio ambiente" supõe que nós, seres humanos, estamos no centro de um sistema de coisas que gravitam em torno de nós, umbigos do universo, senhores e possuidores da natureza (1991, p. 45). Em verdade, a Terra existiu sem os nossos ancestrais e poderia hoje existir sem nós. No futuro, existirá sem nenhum de nossos descendentes. Nós, entretanto, não podemos existir sem ela.

\section{5 - Sumária apreciação. 3.5.1 - Natureza infra-humana como sujeito} jurídico. É abundante o discurso de Serres, no sentido de propor a transformação dos objetos, da natureza como um todo, em sujeitos de direito, a fim de que o mundo seja levado em conta para a conquista de um equilíbrio final (1991, p. 49-51). Assim, interpreta como parasitismo a tese de que só o homem é sujeito de direito e postula uma "revisão dilacerante" do direito natural moderno (1991, p. 51). Ora, de acordo com a tradição, só a pessoa é sujeito de direito em sentido próprio. A defesa dos demais viventes, e da própria natureza não-animada, não requer sejam transformados em sujeitos jurídicos. O objetivo de proteção pode e deve ser alcançado pela atuação dos deveres e da responsabilidade dos humanos, no sentido de usar de tudo em conformidade com a reta razão. Direito subjetivo, aliás, é poder moral, que se dirige à inteligência e à vontade dos sujeitos que os podem compreender e exercitar, por si ou por outrem. Atribuir formalmente direitos 
aos seres infra-humanos, incapazes dessa compreensão, representa um forte contra-senso ético e jurídico. Pode ser aceito apenas em sentido figurado, impróprio, análogo - uma espécie de "direito germinal", como o que Otfried Höffe postula para os animais (Höffe, 2003, p. 110).

\subsection{2 - Cosmocentrismo - O antropocentrismo da tradição científica e} tecnológica ocidental, Serres o substitui por um cosmo ou fisiocentrismo, com retorno implícito aos antigos gregos. De acordo com o autor, "é preciso colocar as coisas no centro e nós em sua periferia, ou, melhor ainda, elas por toda parte e nós em seu meio, como parasitas" (1991, p. 46).

Pelas mesmas razões já expendidas, também deve ser rejeitada a perspectiva cosmocêntrica aqui proposta. O reordenamento das relações do homem com os seres infra-humanos, vistas antes como de administrador e não de dono absoluto e arbitrário das coisas, não requer a capitis deminutio ou a desqualificação do ser humano e a antropomorfização da natureza. Sem o homem como ponto de referência, não é possível estruturar qualquer ética digna de apreço. Em verdade, um antropocentrismo razoável, na elaboração de qualquer ética ao nível da reflexão puramente racional, parece incontornável.

3.5.3 - Mérito. Michel Serres tem o mérito, ao lado de outros autores proeminentes da atualidade, de estimular o debate em torno das questões ambientais, hoje visualizadas como de vida e morte da humanidade. Já foi dito que o conjunto desses problemas constitui a "nova questão social" (Höffe, 2003, p. 105), a ser superada pela participação solidária de todos, Estados, Igrejas, associações, poderes, cidadãos. No debate dessa problemática, o estabelecimento de uma "ética coletiva" (1991, p. 71), conforme a proposta de Serres, parece mesmo indispensável para a sobrevivência não só dos humanos como de toda a vida no Planeta. 
4 - Proposta de Peter Singer. 4.1 - Nova ética. Singer proclama: “Não aprovo nenhuma ética gravada em pedra" (1997, p. 187) e prega "uma completa transformação..., uma drástica mudança na velha ética" (1997, p. 215). Pretende uma "ética revisada" (1997, p. 202), "completamente nova" (1997, p. 216), sem necessidade de apoiar-se em "ficções nas quais ninguém pode acreditar realmente" (1997, p. 18), uma ética que desse "prioridade à qualidade de vida sobre a santidade da vida, ao menos no que se refere ao feto" (1997, p. 100, 124).

Para Singer, este "é o momento de outra revolução copernicana" (1997, p. 187). Temos de "mudar nossa tendência de ver os seres humanos como o centro do universo ético" (1997, p. 187). Por isso, o autor problematiza a distinção específica defendida pela ética tradicional entre os seres humanos e todos os outros animais (1997, p. 166), o que leva a considerar sacrossanta a vida de um bebê anencefálico contrariamente à dos gibões, em relação aos quais o ser humano é livre para os matar. Deveríamos renunciar à resposta tradicional a essa questão, sem cabida, e "revisar as fronteiras da nossa ética" (1997, p. 182).

Para a transformação completa da velha ética, segundo Singer, basta mudar dois supostos, ambos de origem religiosa: 1 - o de que somos responsáveis pelo que fazemos intencionalmente, mas de certo modo não o somos pelo que não impedimos deliberadamente; 2 - o de que as vidas de todos os membros de nossa espécie, e só deles, merecem maior proteção que a vida de qualquer outro ser (1997, p. 215).

4.2 - Mandamentos antigos e novos. Segundo Singer, uma nova proposta ética pode adotar diferentes formas (1997, p. 216). Na estruturação de sua proposta acerca da vida e da morte, tem a pretensão de reescrever cinco mandamentos da velha ética, que julga "falsos" (1997, p. 187). Confere ao 
que pretende um "caráter preliminar de esboço" (1997, p. 203): "esboço de uma nova ética" (1997, p. 214). Os mandamentos antigos e os novos são os seguintes:

1을 Antigo: Considerar que toda vida humana tem o mesmo valor. 10 Novo: Reconhecer que o valor da vida humana varia (1997, p. 188). "O melhor argumento em favor do novo mandamento é o absurdo do antigo" (1997, p. 189).

2o Antigo: Nunca pôr fim intencionalmente a uma vida humana inocente (1997, p. 190). 20 Novo: Responsabilizar-se pelas conseqüências de suas ações (1997, p. 192).

3ㅇ- - Antigo: Nunca tirar a própria vida e sempre procurar evitar que outros tirem a deles (1997, p. 194). 3ㅇ - Novo: Respeitar o desejo de viver ou morrer de uma pessoa (1997, p. 195).

4o Antigo: Crescer e multiplicar-se (1997, p. 195). “É pouco ético fomentar mais nascimentos" (1997, p. 196). 4ํ Novo: Só trazer ao mundo crianças desejadas (1997, p. 197).

5o Antigo: Sempre considerar qualquer vida humana mais valiosa do que qualquer vida não-humana (1997, p. 198). 50 Novo: Não discriminar por razão da espécie (1997, p. 199).

4.3 - Sumária apreciação. Obviamente, os princípios de Singer não poderiam não ressumbrar seu conseqüencialismo, o rebaixamento do Homo sapiens ao nível dos animais não-pensantes, o reconhecimento da autonomia ilimitada das pessoas, o não-discernimento de meios lícitos e ilícitos para trazer ao mundo crianças desejadas. É intuitivo que se impõe a cada qual responsabilizar-se pelas conseqüências de suas ações. Sempre foi uma exigência da ética tradicional. Porém, as conseqüências - uma das circunstâncias que influem na moralidade dos atos humanos - não 
representam o único parâmetro para agir. Também é preciso atentar para princípios, a fim de evitar o puro conseqüencialismo. O "crescei e multiplicaivos" da ética velha também está sujeito a limites, impostos pela responsabilidade dos pais, não porém através de quaisquer meios. A autonomia das pessoas no viver e morrer é um princípio apenas prima facie; em caso de conflito, cede o passo ao princípio da não-maleficência, ou do neminem laedere, que é um princípio absoluto. A adscrição à espécie homo sapiens atribui ao ser humano uma dignidade ímpar, que não pode ser sonegada, sob pena de solaparem-se os próprios fundamentos da ética. Ver a respeito Reinhard Merkel (2003, p. 60-75).

Peter Singer critica com veemência a ética tradicional. Não raro, sua crítica é equivocada e de má interpretação da ética clássica. Assaca contra ela que não leva em conta a qualidade de vida, mas tão-só a santidade da vida humana (1997, p. 126), o que não é verdade. Uma das razões pelas quais o autor procura justificar a eutanásia voluntária e o suicídio, é a renunciabilidade do direito. Não se dá conta de que a ética e o direito tradicional reconhecem direitos irrenunciáveis, como são os direitos fundamentais e personalíssimos, entre os quais assoma como primeiro e pressuposto dos demais o direito à vida.

Por outro lado, Singer é irremediavelmente tributário da ética tradicional, em que ele não deixa de situar-se. De saída concorda com a tradição segundo a qual "não podemos viver sem uma ética" (1997, p. 203). As questões básicas de sua proposta são do patrimônio da sabedoria do Ocidente. Corretamente afirma que "somos responsáveis por nossas omissões da mesma forma que por nossos atos" (1997, p. 192). Aliás, Singer admite "peças de verdade" da ética tradicional, tais como um grau moderado de parcialidade para conosco mesmos, nossas famílias e nossos amigos" (1997, p. 193). Não recusa que pode haver razões "para preservar ao menos uma 
parte da distinção tradicional entre matar e permitir morrer - por exemplo, sustentar que é pior matar pessoas alheias que deixar de dar-Ihes a comida que necessitam para sobreviver" (1997, p. 193). E ainda afirma que "na vida cotidiana há boas razões para que a proibição do assassinato seja mais estrita que a do permitir morrer" (1997, p. 193). Com isso, curva-se à distinção que anteriormente tanto combateu. Admite que "a aceitação universal e a segura proteção do direito à vida de todas as pessoas é o bem mais importante que uma sociedade pode conceder a seus membros" (1997, p. 213). Esta é também uma tese da ética e do direito da tradição ocidental, embora sem a extensão do conceito de pessoa a animais não-humanos. Por fim, Singer fala em "natureza humana", sem pejo, como se pode ver em vários excertos (1997, p. 164, 193). Contudo, o conceito dele não funciona à moda da filosofia antiga, pois, afirma que "ser membro da espécie homo sapiens não pertence à ética" (1997, p. 202).

É verdade, Singer inaugura algumas dissidências em relação à ética tradicional. A querer instaurar uma ética totalmente nova, teria que abandonar toda a herança da tradição que incorporou em seu pensamento. Em sua linguagem iconoclasta, todavia, pretende eliminar o tronco do qual ele mal representa um ramo. Corte do tronco o galho em que está sentado e veja se ficará pendurado... no ar... qual pintor no pincel... Fúrias iconoclastas passarão; a serena verdade do senso comum permanecerá e conhecerá aperfeiçoamentos, com achegas pertinentes.

5 - Outros autores. Há outros autores que falam linguagem semelhante, eventualmente de modo mais esporádico. Apresento alguns, dentre outros, à guisa de exemplo.

René Rémond afirma que para questões de "absoluta novidade e de gravidade", tais como: a energia liberada pela fissão atômica, as descobertas 
das ciências da vida, na área da biologia, especialmente da genética, "as respostas tradicionais são totalmente inadaptadas ou caducas", em vista do que são necessários "novos critérios"... (2003, p. 358, col. 2).

Bernardo Erdmann, dissertando sobre transgenia, afirma que, "para os novos conceitos, necessita-se de uma nova moral" (2003, p. 137).

Ernildo Stein sustenta que os difíceis problemas de julgamento e decisão, que emergem da tecnologia genética, "não se resolverão através do recurso a diretrizes da ética tradicional para decidir o que pode ser experimentado, o que deve ser visto como aceitável ou o que deve ser proibido" (2003, p. 147).

José Renato Nalini também postula uma "nova ética", uma "nova ética de conservação e gestão dos já combalidos recursos naturais..." (2001, p. XXXVIII). mais precisamente, uma "nova ética política... novos direitos culturais e coletivos" (2001, p. XXXI).

Manfredo Araújo de Oliveira se bate por uma nova ética, não antropocêntrica como a ética da modernidade (1997, p. 196); uma ética que não será mais simplesmente uma ética subjetiva ou intersubjetiva, situada na tradição de Kant, mas uma ética ontológica, não limitada a uma teoria da sobrevivência do indivíduo. Em última instância, deverá ser uma teoria da coerência do indivíduo com todos os outros homens e com a natureza (1997, p. 197-198), uma ética comprometida com a dignidade maior da vida humana e com a solidariedade e complementaridade de todos os seres, em coerência com o todo $(1997$, p. 198199).

Leonardo Boff também luta por uma nova ética, que deveria emergir de uma nova ótica, da substituição da inteligência instrumental-analítica, da qual vem o rigor científico, pela inteligência emocional-cordial, da qual derivam as imagens e os mitos (2001, p. 28 e 37). "Uma ética nova pressupõe uma ótica nova" (2001, p. 22), E continua: "Importa construir um novo ethos que permita uma nova convivência entre os humanos com os demais seres da comunidade biótica, planetária e cósmica... " (2001, p. 27). A nova ética deveria ser uma "ética do 
cuidado" (2001, p. 134). "É urgente um novo ethos de cuidado, de sinergia, de religação, de benevolência, de paz perene para com a Terra, para com a vida, para com a sociedade e para com o destino das pessoas, especialmente das grandes maiorias empobrecidas e condenadas da Terra" (2001, p. 39). De outra parte, a ética do cuidado exige também uma nova espiritualidade, "uma espiritualidade simples e sólida, baseada na percepção do mistério do universo e do ser humano, na ética da responsabilidade, da solidariedade e da compaixão... " (2001, p. 25).

Leonardo Boff, trocando de registro, fala em "novo paradigma de convivência", em "novo pacto social", his verbis: "Precisamos de um novo paradigma de convivência que funde uma relação mais benfazeja para com a Terra e inaugure um novo pacto social entre os povos no sentido de respeito e de preservação de tudo o que existe e vive" (2001, p. 17-18). O primeiro parágrafo do novo pacto social entre os povos sobreviventes [de possível catástrofe de dimensões apocalípticas] deveria definir o dever de autolimitar-se e de viver sob a justa medida, no cuidado para com a herança recebida do universo, na ternura essencial para com os humanos e no respeito pelos outros seres da criação" (2001, p. 125). Isso representaria "um novo paradigma civilizatório" (2001, p. 21), "mais propício à vida, na justiça e na fraternura (sic) entre todos" (2001, p. 126).

Gregório Robles também postula "um novo pacto: o pacto que nos impulsione à contemplação da humanidade como um todo e nos permita salvar-nos juntos. Não um pacto a favor do Estado, como os modernos, senão um pacto a favor da humanidade" (1995, p. 185; apud Nalini, 2001, p. XXXIX-XL).

Os autores mencionados neste artigo, alguns dentre os mais renomados na atualidade, não esgotam a lista dos que postulam uma ética nova, ou um novo contrato social. O exposto acerca de suas opiniões, contudo, parece o suficiente para o meu propósito, que é justificar a desnecessidade de uma novidade absoluta na ética, por entender que é suficiente atualizá-la e 
complementá-la, de acordo com as exigências de tempo, espaço e condição das pessoas e dos povos. Para isso julgo haver boas razões, como direi.

6 - Desnecessidade de uma ética radicalmente nova. Salvo melhor juízo, não se faz necessária uma ética radicalmente nova. Em sentido contrário ao das posições extremadas, iconoclastas, parece oportuno afirmar que não é preciso rejeitar a ética tradicional como um todo, para garantir respeito aos animais e à própria natureza. Decerto, não se requer a outorga de direitos a eles, para lograr sua proteção. É que o homem, na sua qualidade de "animal racional", tem o dever emergente de sua própria natureza de usar racionalmente as criaturas, inclusive os brutos, ou seja, os animais desprovidos de razão - sem crueldade, sem desperdício, sem danos irreversíveis, sem sofrimentos inúteis, mas com sustentabilidade. Isso por certo não exige que se os transforme em sujeitos éticos e jurídicos. Em outras palavras, a justa proteção tão desejada se obtêm, sem outorga de direitos a coisas e brutos, que sequer podem exercê-los.

7 - Lei natural: conclusões e determinações. O que se impõe, certamente, é explicitar, a partir dos princípios comuns da lei moral natural, os deveres emergentes do homem em relação à natureza como um todo; e, principalmente, urgir com rigor o seu cumprimento. Trata-se, em linguagem da tradição, de extrair novas conclusões e formular determinações ou especificações novas dos velhos princípios da lei natural (Nedel, 2000, p. 110112). Hão de ser conclusões e especificações novas dos velhos princípios da ética ocidental, que sejam adequadas às condições atuais da humanidade, tendo em vista as recentes conquistas da ciência e da tecnologia.

De efeito, em seus princípios gerais, a lei natural prescreve: bonum est faciendum - malum est vitandum, ou seja, deve-se fazer o bem e evitar o mal 
(T. de Aquino, Summa. theologiae, I-II, 94, 2). Desses princípios (primeira classe) são deduzidos preceitos, por conclusões fáceis, imediatas, como os constantes do Decálogo - fora o terceiro, que é preceito positivo (segunda classe), e por conclusões mais difíceis, remotas, como os preceitos relativos às propriedades do casamento, à ilicitude da mentira, do duelo etc. (terceira classe).

Por sua vez, a lei positiva (humana) se estrutura mediante conclusões (próximas e remotas) da lei natural e ainda através de determinações ou especificações do que se contém de modo geral nos princípios, como a organização do Estado, com seus poderes, a especificação das penas para os delitos, a forma do exercício da autoridade, o modo de realização da justiça na comunidade, que deve agora incluir previsão para as questões novas emergentes do avanço científico e tecnológico. Dessa maneira, constitui-se o conjunto das leis justas, todo ele derivado da lei natural, de uma forma ou de outra. Assim, o inteiro sistema dos princípios e normas éticas e jurídicas, no jusnaturalismo clássico, adquire unidade perfeita, formal e substancial, em contraposição ao sistema juspositivo, cuja unidade é apenas formal.

8 - Processo continuado de invenção. É de ver que o processo de invenção de normas de conduta, quer individuais, quer sociais, a partir dos preceitos mais genéricos da lei natural, não está findo - aliás, jamais estará, enquanto houver história humana. Em cada época, ante novas circunstâncias, não só é possível mas também necessário inventar normas inéditas de conduta, a partir de princípios perenes invariáveis no tempo e no espaço. Destarte, a lei natural, imutável na essência, adquire historicidade em suas aplicações concretas, de acordo com as exigências do tempo. Em conseqüência disso, a ética é renovada, mas não de todo, não radicalmente, pois o núcleo dela, com seus pontos arquimédicos, permanece e orienta toda e qualquer renovação. 
Com essa orientação, escreve Francesco Bellino. "O trabalho filosófico, sobretudo na ética, não consiste tanto em construir novos princípios e inventar novos valores, quanto sobretudo, no fazer aflorar na consciência reflexa o que já está presente na consciência não-reflexa, no tornar tema aquilo que de qualquer maneira permanece atemático... [No mais,] tornar explícito o implícito é uma das tarefas fundamentais da investigação filosófica... " (1997, p. 32). Mais adiante o mesmo autor sustenta que as inovações tecnológicas impelem a ética, não a encontrar novos princípios, mas em desenvolver "todas as implicações relevantes dos princípios que ela já tem". Em vista disso, também não considera a bioética como uma nova ética, mas como "a mesma velha ética aplicada a um particular setor da problemas". De fato, "a novidade dos problemas e dos contextos de aplicação não comporta o abandono da ética geral e de sua substituição por uma nova ética" (1997, p. 64).

6 - Ponderações finais. Como é intuitivo, não se postula a rejeição da moral comum e a instauração de uma totalmente nova. Exigem-se apenas, de acordo com as circunstâncias atuais, novas complementações da velha ética consagrada pelo bom senso da humanidade, mediante procedimentos adequados. A rejeição da tradição in totum, em nome de uma pretensa novidade absoluta, não é sinal de sabedoria. Todo discurso intemperante nos termos, demolidor e iconoclasta, pode ser havido como suspeito de parcialidade, quando não de equívoco manifesto.

Assim sendo, não é de ser acolhida a pretensão de criar uma ética totalmente nova, a teor da pregação de alguns dos próceres da ética aplicada examinados neste ensaio. Em vez disso, parece necessário e suficiente extrair dos velhos princípios consagrados (como os do neminem laedere - não lesar ninguém, e do ius suum cuique tribuere - respeitar o direito de cada um) conclusões novas e inventar determinações ou especificações pertinentes, de acordo com o nosso tempo e estágio civilizatório. Assim, todas as questões 
novas surgidas no horizonte da pesquisa científica e de sua aplicação tecnológica poderão ter regulação pertinente. Essa tarefa incumbe à razão prática ornada com a indispensável virtude da prudência e é infindável, aberta que está a uma indefinida perfectibilidade.

Com certeza, impõe-se conhecer e aproveitar as achegas do tempo, na área das ciências e da tecnologia, à medida que revertem para o bem do homem individual e social, que não é menos do que a verdadeira norma da moralidade, como sempre foi na mente dos fautores da ética tradicional e continua sendo nas melhores tentativas de sua atualização. Aliás, o retorno aos clássicos da ciência do éthos que se verifica em nossos dias, é sinal de que sua mensagem continua válida, ao menos na essência, sem prejuízo da sua adaptação ou mesmo renovação parcial, de acordo com as exigências autênticas da atualidade. Destarte, será possível que o equilíbrio entre os diferentes segmentos e ecossistemas da realidade não se rompa ou se restabeleça, e se reconquiste, ou conquiste, a harmonia entre as pessoas e os povos para a sobrevivência da espécie humana e de toda a vida no planeta em sua multifária complexidade.

Boa medida consistirá em superar os exageros de linguagem e a fúria desconstrutiva desencadeada por alguns teóricos contra os valores da tradição, sem fixar-se no imobilismo e saudosismo do passado, para lograr a junção dos valores antigos que permanecem válidos com propostas novas impregnadas de sensatez, ao modo segundo o qual, em outro tempo e contexto, para superar os desafios da modernidade, pregava o sábio humanista Leão XIII, com sua palavra de ordem vetera novis augere et perficere - complementar e aperfeiçoar o antigo com o novo (Aeterni Patris, 1879). Em verdade, tradição e renovação sabiamente combinadas representam a parelha através da qual se fomenta o progresso e o desenvolvimento integral da humanidade, atendendo a quaisquer exigências derivadas da velocidade da história, inclusive nos dias atuais. 


\section{Referências bibliográficas}

AQUINO, Tomás de. Summa theologiae. Madrid: Biblioteca de Autores Cristianos, 1961.

BELLINO, Francesco. Fundamentos da bioética. Aspectos antropológicos, ontológicos e morais. Bauru, SP: EDUSC, 1997.

BACON, Francis. Novum organum, ou verdadeiras indicações acerca da interpretação da natureza. São Paulo: Nova Cultural, 1997-1999.

BOFF, Leonardo. Saber cuidar. Ética do humano. Compaixão pela Terra. 7. ed. Petrópolis, RJ: Vozes, 2001.

COMTE, Auguste. Cours de philosophie positive. Paris: Garnier Frères, 1926.

DESCARTES, René. Princípios de filosofia. 4aㅡ ed. Lisboa: Guimarães, 1989.

ERDMANN, Bernardo. A importância da transgenia na evolução e na formação da Gaia. In: SOUZA, Draiton G. de \& ERDTMANN, Bernardo. Ética e genética II. Porto Alegre: EDIPUCRS, 2003, p. 127-138.

HÖFFE, Otfried. O que é justiça? Porto Alegre: EDIPUCRS, 2003.

JONAS, Hans. El principio de responsabilidad. Ensayo de una ética para la civilización tecnológica. Barcelona: Herder, 1995.

- Técnica, medicina y ética. Sobre la práctica del principio de responsabilidad. Barcelona, Buenos Aires, México: Paidós, 1997.

NALINI, José Renato. Ética ambiental. Campinas, SP: Millenium, 2001.

MERKEL, Reinhard. Direitos fundamentais para a mórula? In: SOUZA, Draiton G. de \& ERDTMANN, Bernardo. Ética e genética II. Porto Alegre: EDIPUCRS, 2003, p. 45-79.

NEDEL, José. Ética, direito e justiça. 2. ed. Porto Alegre: EDIPUCRS, 2000.

OLIVEIRA, Manfredo Araújo de. Tópicos sobre dialética. Porto Alegre: EDIPUCRS, 1997.

RÉMOND, René. Política, In: CANTO-SPERBER, Monique (org.). Dicionário de ética e filosofia moral. São Leopoldo, RS: Ed. Unisinos, 2003, p. 353-359. ROBLES, Gregório. Los derechos fundamentales y la ética en la sociedad actual. Madrid: Civitas, 1995.

SIQUEIRA, José Eduardo de. Ética e tecnociência. Uma abordagem segundo o princípio da responsabilidade de Hans Jonas. Londrina: UEL, 1998. 
SINGER, Peter. Ética prática. São Paulo: Martins Fontes, 1994. ---. Repensar la vida y la muerte. El derrumbe de nuestra ética tradicional. Barcelona/Buenos Aires/México: Paidós, 1997.

STEIN, Ernildo. Existem genes para a moral? In: SOUZA, Draiton G. de \& ERDTMANN, Bernardo. Ética e genética II. Porto Alegre: EDIPUCRS, 2003, p. 147-150.

SERRES, Michel. O contrato natural. Rio de Janeiro: Nova Fronteira, 1991.

VALLS, Álvaro L. M. Da ética à bioética. Petrópolis, RJ: Vozes, 2004.

Doutor em Filosofia, PUCRS

E-mail: jnedel@bage.unisinos.br 